\title{
Caregiver perceptions of the food marketing environment of African-American 3-11-year-olds: a qualitative study
}

\author{
Monica L Baskin ${ }^{1, *}$, Ivan Herbey ${ }^{\text {, }}$ Ronnie Williams², Jamy D Ard' ${ }^{1}$ Nataliya Ivankova ${ }^{1}$ \\ and Angela Odoms-Young ${ }^{3}$ \\ 'Division of Preventive Medicine, University of Alabama at Birmingham School of Medicine, 171711 th Avenue \\ South, MT 618, Birmingham, AL 35205, USA: ${ }^{2}$ Congregations for Public Health, Inc., Birmingham, AL, USA: \\ ${ }^{3}$ Department of Kinesiology and Nutrition, University of Illinois at Chicago, Chicago, IL, USA
}

Submitted 2 May 2012: Final revision received 10 May 2013: Accepted 21 May 2013: First published online 5 July 2013

\begin{abstract}
Objective: To assess caregivers' perceptions of the extent to which the food marketing environment influences food consumption among African-American children (aged 3-11 years) in order to generate potential strategies to make the marketing environment more favourable to healthier eating.

Design: Individual semi-structured interviews with caregivers were conducted by trained community leaders to ascertain their awareness of and perceptions about food marketing environments contributing to African-American children's food consumption.

Setting: Six predominantly African-American communities in metro Birmingham, Alabama, USA with high proportions of school-age children and lower-income residents.

Subjects: Caregivers ( $n$ 25) were predominantly female (93\%) and either parents/ guardians (64\%) or grandparents (28\%) of African-American children aged 3-11 years. Caregiver mean age was 43 years and $46 \%$ had lived in their current residence for over 10 years.

Results: Caregivers reported all aspects of the food marketing matrix as supporting unhealthy eating among African-American youth. Child preference for foods higher in fat and sugar, lower pricing of less healthy foods, limited access to healthier food retailers and targeted advertisements were particularly influential on the food selection, acquisition and consumption of children. Company loyalty, corporate sponsorship of local events and conflicts over parental $v$. food company responsibility contributed to less consensus about the overall impact (positive or negative) of food companies in African-American communities.

Conclusions: While caregivers perceived aspects of their food marketing environments as primarily contributing to unhealthy eating among African-American children, framing the demand for changes in the food marketing environments of African-American youth may be particularly challenging.
\end{abstract}

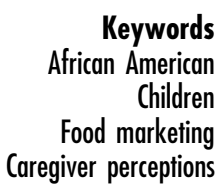

Nearly one in three children in the USA is overweight or obese (BMI $\geq 85$ th percentile for age and sex $)^{(1)}$. Obesity is associated with increased risk of multiple health consequences in youth, including asthma, sleep apnoea, type 2 diabetes, early puberty, depression, low self-esteem and teasing ${ }^{(2-4)}$. Additional risks when obesity continues into adulthood include hypertension, CVD and certain cancers $^{(5,6)}$. Childhood obesity rates have generally increased among all racial/ethnic groups in the USA; however, AfricanAmerican youth, on average, experience higher rates of excessive weight and related health burdens ${ }^{(7-10)}$. Differences in health behaviours (e.g. diet and physical activity) have been partially implicated ${ }^{(11-13)}$, along with environmental contributors, including food marketing ${ }^{(14)}$.
Marketing is viewed as comprising four key elements known as the 4 Ps: product, price, place and promotion $^{(15)}$. Product is the tangible or intangible goods and services that meet the needs and desires of the customer. Price is what the customer is willing to exchange or pay for the product and includes both monetary and nonmonetary costs. Place is how the customer gets to access the product. Promotion references a variety of strategies (e.g. advertising, branding, publicity) used to get the word out that the product is available. These 4 Ps are directly controlled by food marketers and evidence suggests that the manipulation of product, price, place and promotion contributes to both unhealthy diets and overconsumption of food ${ }^{(16-20)}$. 
Elevated exposure to food marketing may increase preference and demand for certain foods, brand loyalty and psychological associations between selected food items and activities, toys, games, characters and/or celebrities $^{(14,21,22)}$. Comprehensive reviews document elevated levels of advertisement of foods of minimal nutritional value by promoting products using channels with high utilization among youth (e.g. television, Internet, cross-promotions with movies) ${ }^{(18,22,23)}$. As such, the food marketing environment may contribute to overconsumption of dietary energy.

Targeted marketing involves identifying a group of people with shared characteristics or need and matching the product, price, place and promotion activities to the preferences of that group ${ }^{(24)}$. Targeted marketing practices have been linked to diet and obesity disparities ${ }^{(25-27)}$. The food marketing environment represents the totality of the surroundings and conditions in which an individual is exposed to practices aimed at encouraging the acquisition and consumption of foods and beverages ${ }^{(25-27)}$. The food marketing environments of African-American consumers are less likely to support the development and maintenance of healthful eating and may predispose African Americans to excess energy consumption ${ }^{(25)}$. AfricanAmerican youth (compared with their white counterparts) have greater exposure to advertisements of foods and beverages of low nutritional value and high energy content during their most watched programmes ${ }^{(28,29)}$. Taken together with greater media usage of African-American youth $^{(30)}$, overall exposure to the promotion of unhealthy and high-energy foods may far exceed that of their white peers.

Marketing of high-energy foods to youth has been recognized by researchers ${ }^{(14,16)}$, public health authorities $^{(22,31)}$ and federal regulators ${ }^{(32)}$ as contributing to less healthy diets and/or overconsumption of energy. The US Institute of Medicine ${ }^{(22)}$ and the $\mathrm{WHO}^{(31)}$ have called for self-regulation and government intervention to ensure reductions in marketing of unhealthy foods to children. Others have suggested grass-roots or social/environmental justice movements, particularly in lower-income and minority communities, to help develop and enforce policies to support neighbourhood environments with healthy choices for all segments of the community ${ }^{(33)}$. For example, active involvement of community residents in pointing out to policy makers the limited availability or access to health-promoting resources (e.g. healthier food choices) due to structural disadvantages related to a specific population (e.g. lower socio-economic status, minority) and demanding corrective action.

Despite these recommendations, public support for food marketing restrictions has yet to reach levels suggesting sufficient political leverage for legislative or regulatory interventions ${ }^{(16,34,35)}$. Limited public support may be, in part, due to a lack of public awareness of children's daily exposure to food marketing and/or its health consequences ${ }^{(35-37)}$. There is conspicuously limited published literature related to consumer awareness and attitudes concerning food marketing exposure of children. More in-depth understanding of parental perceptions is critical for intervention development. Further, what does currently exist in the published literature focuses on general $v$. ethnic-specific perceptions. Recent studies examining perceptions of the food marketplace suggest differences in perception among ethnic groups ${ }^{(38)}$ and between adults and teens ${ }^{(39)}$.

The purpose of the present study was to examine caregivers' perceptions of the extent to which the food marketing environment contributes to dietary behaviours of African-American children (aged 3-11 years) residing in predominantly African-American communities. Given the dearth of literature on this topic and with this target population in particular, the study was exploratory in the hope of gaining a more in-depth understanding of caregiver perceptions of children's exposure to general and targeted food marketing and consequences on children's eating behaviours. Findings from this research are intended to inform potential strategies to address the food marketing environment to promote healthier eating among AfricanAmerican children and families.

\section{Methods}

\section{Setting and study design}

The study was conducted in Birmingham, Alabama, a large urban city located in the south-eastern USA. The largest city in the state, Birmingham's population is $62 \%$ African American. Nearly 28\% of households include children and the median family household income is about \$US $32000^{(40)}$.

The study design utilized a community-based participatory research (CBPR) approach ${ }^{(41)}$. CBPR is a methodology that acknowledges the value of both the 'researcher' and the 'participant' in the full process of scientific inquiry through the formation of partnerships between academic researchers and community members for the active participation in the study design, data collection and interpretation of findings. Further, CBPR is a process with the ultimate goal of social change to improve community health. The present study is part of ongoing research to support changes in community systems, programmes and/or policies that may contribute to obesity-related health disparities in the USA. To conduct the study, we partnered with Congregations for Public Health, Inc. $(\mathrm{CPH})$, a non-profit organization comprised of six African-American churches located in older Birmingham neighbourhoods with high proportions of African Americans, school-age children and lower-income households (see Table 1$)^{(42)}$. The mission of $\mathrm{CPH}$ is to address the public health concerns of residents living in neighbourhoods within a 1 mile $(1.6 \mathrm{~km})$ radius of each church. 
Table 1 Neighbourhood characteristics of study participants: caregivers $(n$ 25) of African-American children aged 3-11 years from six primarily African-American communities in metro Birmingham, AL, USA

\begin{tabular}{lccr}
\hline Neighbourhood characteristic (by zip code) & Minimum & Maximum & Average \\
\hline Percentage of African Americans & $65 \cdot 4$ & $96 \cdot 6$ & $88 \cdot 98$ \\
Percentage of families below the poverty level & $11 \cdot 0$ & $30 \cdot 3$ & $23 \cdot 23$ \\
Median household income (\$US) & 17999 & 34468 & 24159 \\
Percentage of school-age children & $16 \cdot 7$ & $21 \cdot 2$ & $19 \cdot 97$ \\
\hline
\end{tabular}

Source: US Census Bureau ${ }^{(42)}$.

Trained Neighborhood Outreach Specialists (NOS) assigned to each church provide community outreach, conduct health promotion activities and assist with data collection.

\section{Procedures}

NOS recruited caregivers of young children from their church catchment area using previously successful methods including fliers, word of mouth and direct contact via other outreach efforts. While the target population for the study was caregivers of young African-American children, we recognized the heterogeneity within this subset of the population. As such, a purposive sampling approach was used to try to recruit participants who represented a range of demographic characteristics (e.g. family composition, socio-economic status, neighbourhood of residence) that might result in divergent perceptions of the food marketing environment to better inform our exploratory study. Each potential participant was screened for inclusion criteria (i.e. neighbourhood resident, caregiver of a 3-11-year-old African-American child, English-speaking) and provided information about the study's purpose, procedures, risks and benefits. The study was conducted according to the guidelines laid down in the Declaration of Helsinki and all procedures involving human subjects were approved by the University of Alabama at Birmingham. Written informed consent was obtained from all study participants.

Individual semi-structured ethnographic interviews ${ }^{(43)}$ with study participants were held at participating $\mathrm{CPH}$ church locations or other convenient public locations within the community (e.g. community centre). Each interview was conducted by a trained interviewer using a semi-structured protocol that focused on the following topics: knowledge and attitudes about child eating behaviours; attitudes and beliefs about the influence of food marketing on child food and beverage consumption; and opinions about efforts to limit food marketing directed at children.

Interviews were audio-recorded and transcribed verbatim by a commercial transcription company. Transcribed interviews were analysed inductively using a software program for qualitative data analysis (NVivo9). A standard thematic analysis ${ }^{(44)}$ was conducted to search for common categories and themes in the data. Two independent coders, experienced in qualitative research, initially coded a sample of interviews to develop the coding tree.
After independent assessment, coders, in collaboration with study investigators, added and revised codes until consensus on a final coding scheme was reached. Subsequently, each interview transcript was independently coded by the two original coders. Coders identified key points and recurring categories and themes that were central to the experiences described by the participants. The process consisted of dividing the text into semantic segments, labelling the segments with codes, examining the codes for overlap and redundancy, and aggregating these codes into broader categories and themes ${ }^{(44)}$. A constant comparative $\operatorname{method}^{(45)}$ was employed to generate semantically rich codes, categories and themes.

\section{Results}

A summary of findings from interview analyses along with a discussion of different views presented are offered below. Selected participant quotations are included throughout to bring the participant's voice to life, as well as to illustrate the range of responses provided.

\section{Participant and neigbbourbood characteristics}

Participants were primarily female (23/25) with a mean age of 43 years. Primarily parents/guardians (64\%) or grandparents $(28 \%)$ of young children participated in the study. Participants tended to be single $(56 \%)$ and to be the caregiver for two or more children between the ages of 3 and 11 years (44\%). All participants resided in the neighbourhoods surrounding the six churches of $\mathrm{CPH}$. As noted earlier, these neighbourhoods include primarily African-American and low-income residents. Nearly half (46\%) of caregivers had lived in their current residence for more than 10 years. Additional demographic information is provided in Table 2 .

\section{Child eating bebaviours, consequences and parenting practices}

Caregivers described their beliefs about important foods for children to eat and/or limit, concerns about their child's eating behaviours and general strategies used to guide children's eating. They expressed the need for children to eat a diet consistent with recommended dietary guidelines (e.g. fruit, vegetables, whole grains, low-fat dairy products, lean protein) and avoid 'junk' 
Table 2 Demographic characteristics of study participants: caregivers ( $n$ 25) of African-American children aged 3-11 years from six primarily African-American communities in metro Birmingham, AL, USA

\begin{tabular}{|c|c|c|c|}
\hline Variable & Range & Mean & SD \\
\hline Caregiver age (years) & $18-74$ & $43 \cdot 04$ & $14 \cdot 26$ \\
\hline Child age (years) & $3-11$ & $5 \cdot 96$ & $2 \cdot 75$ \\
\hline \multirow{2}{*}{ Time living at residence (months) } & $12-540$ & $160 \cdot 24$ & $141 \cdot 02$ \\
\hline & $n$ & $\%$ & \\
\hline \multicolumn{4}{|l|}{ Caregiver gender } \\
\hline Female & 23 & 92 & \\
\hline Male & 2 & 8 & \\
\hline \multicolumn{4}{|l|}{ Caregiver relationship to child(ren) } \\
\hline Parent/guardian & 16 & 64 & \\
\hline Grandparent & 7 & 28 & \\
\hline Aunt/uncle & 1 & 4 & \\
\hline Child-care provider (not related) & 1 & 4 & \\
\hline \multicolumn{4}{|c|}{ Number of children aged $3-11$ years in the home } \\
\hline One & 14 & 56 & \\
\hline Two & 8 & 32 & \\
\hline Three & 3 & 12 & \\
\hline \multicolumn{4}{|l|}{ Child gender* } \\
\hline Female & 10 & 40 & \\
\hline Male & 14 & 56 & \\
\hline \multicolumn{4}{|l|}{ Caregiver highest education } \\
\hline Some high school & 1 & 4 & \\
\hline Graduated high school or GED & 4 & 16 & \\
\hline Some college & 13 & 52 & \\
\hline Associate's degree or higher & 1 & 4 & \\
\hline Bachelor's degree or higher & 6 & 24 & \\
\hline \multicolumn{4}{|l|}{ Caregiver marital status } \\
\hline Single & 14 & 56 & \\
\hline Married & 10 & 40 & \\
\hline Separated & 1 & 4 & \\
\hline \multicolumn{4}{|l|}{ Household incomet } \\
\hline Less than \$US 10000 & 5 & 21 & \\
\hline \$US $10000-29999$ & 11 & 46 & \\
\hline \$US $30000-49000$ & 6 & 25 & \\
\hline \$US 50000 and above & 2 & 8 & \\
\hline \multicolumn{4}{|l|}{ Participation in public assistance } \\
\hline Yes & 9 & 36 & \\
\hline No & 16 & 64 & \\
\hline \multicolumn{4}{|l|}{ Types of public assistance } \\
\hline Alabama food stamps & 6 & 67 & \\
\hline School Breakfast/Lunch Program & 5 & 56 & \\
\hline WIC & 2 & 22 & \\
\hline Family assistance & 2 & 22 & \\
\hline Unemployment & 1 & 11 & \\
\hline Disability & 1 & 11 & \\
\hline \multicolumn{4}{|l|}{ Time at current residence } \\
\hline Less than 5 years & 8 & 32 & \\
\hline $6-10$ years & 5 & 20 & \\
\hline $11-15$ years & 2 & 8 & \\
\hline More than 15 years & 10 & 40 & \\
\hline
\end{tabular}

GED, General Education Development; WIC, Special Supplemental Nutrition Program for Women, Infants, and Children. *Gender of the first child (if there are multiple children aged 3-11 years in the home).

tData missing for one participant.

foods (e.g. chips, sodas, candy, other sweets). Participants believed such a diet helps children to take in appropriate vitamins and nutrients to maintain adequate energy for growth and development. Similarly, caregivers appeared to be well aware of negative health consequences of poor diet and excess energy intake. They identified several health problems linked to dietary behaviours, including obesity and chronic diseases such as diabetes, hypertension, cancer and dental caries. In addition, caregivers noted that unhealthy choices of foods and overconsumption may also lead to increased financial burden (e.g. medical costs). While some expressed concerns about their child's current dietary habits and future well-being, others did not see an immediate concern.

Regardless of the perceived risk for negative health for children in their care, caregivers described general practices to encourage children to eat healthier including setting and enforcing rules about healthy eating, limiting 
the amount of less healthy foods, and creative cooking where healthier items (e.g. vegetables) are added to dishes or substituted for less healthy items and healthier cooking preparation methods are used (e.g. baking $v$. frying):

'Because I am the parent, in order for you to be able to eat some of the junk food that you want, you must eat the vegetables that I prepare.'

'I did this baked chicken but you use Bisquick ${ }^{\circledR}$... cook it in the oven and they thought it was really fried chicken.'

\section{Perceptions of the food marketing matrix}

Caregivers expressed high confidence in parenting strategies to manage the child's diet, but they described challenges with maintaining a balanced and lower-energy diet due to influences beyond their control. These challenges are presented according to the 4 Ps of the marketing matrix: product, price, place and promotion.

\section{Product}

Caregivers described the foods and beverages the children in their care generally eat and concerns about these items. Some noted that their children regularly consumed healthier foods, particularly when authoritative parenting practices were in place. However, participants more often described children's favourite foods as consisting of chicken (often fried), fast foods (e.g. hamburgers, hot dogs, pizza, French fries) and 'junk' foods (e.g. chips, sodas, candy, other sweets). These items represented most of the specific requests by children. Some caregivers expressed concern about preference for these foods with higher fat, sugar and/ or salt content, as these were also the foods participants most associated with health problems.

\section{Price}

Caregivers noted that foods that are higher in nutritional value and lower in energy (e.g. produce, lean meats, whole grains) compared with less healthy foods are often more expensive and place a particularly high burden on families with limited incomes. While caregivers reported that the healthier option would be better for them/their child, multiple participants pointed to the higher cost of healthier items. Participants admitted to often succumbing to the appeal of cheaper, less healthy items and low-cost combos (e.g. sandwich, fries and soda) and bundled foods (e.g. 2 for $\$ 5$ ) as they were believed to offer greater financial value (i.e. more food for the money):

'I was trying to get a turkey sandwich and they offered you white bread or wheat bread so the white bread on the sandwich was $\$ 2 \cdot 59$, so I asked for the wheat and the price changed it to $\$ 3.59$ and I said it is the same sandwich and he said but it is wheat bread and wheat bread costs more than white bread.'
The issue of higher costs of grocers selling healthier items was not lost on one caregiver who offered the following:

'I noticed that you could not find asparagus or artichoke hearts, not the can ones but I am talking about the real fresh ones you could not find them [in local store]. So when I asked the store manager he told me well ma'am when I bought those kinds of things, I lost money on them because nobody bought them and you know they just rotted and I lost money, so I do not stock them.'

\section{Place}

Participants frequently commented about the lack of availability of stores and restaurants offering healthier foods in their neighbourhood. As such, caregivers generally believed that healthier options were either unavailable or inaccessible to many families. Caregivers described their neighbourhoods as including only convenience or corner stores rather than grocery stores or supermarkets that generally sell a larger variety of foods. The smaller convenience/corner stores were seen as locations to purchase low-cost and less healthy items:

'Most older communities had little corner stores. I think that down near the schools, there are still little stores there, so on the way to school, they'll stop and get a bag of junk, and on the way back home, they will stop also. I think that's a big influence on what they eat.'

Similarly, participants mentioned the presence of more fast-food than sit-down restaurants in their neighbourhoods. The most frequently reported restaurant for eating out was McDonald's ${ }^{\circledR}$ and often it was located within the neighbourhood.

\section{Promotion}

Caregivers reported that some of the greatest influences on children's food and beverage intake were commercials and print ads supporting the purchase and consumption of certain foods. While promotion is part of the marketing matrix of all products, caregivers noted that food marketers use several techniques to appeal specifically to African-American children and families. Participants described the inclusion of African-American children and families, celebrities (e.g. actors, music artists, sports figures) or characters (e.g. from cartoons, movies, television shows) with high popularity among African Americans, and ethnic music, as particularly influential. They further suggested that commercials that are run during shows with higher African-American viewership will have greater impact on purchasing decisions:

'If we see black people in commercials - African Americans in commercials - we're going to be more 
prompt, I believe, to buy. So, you see African Americans in Burger King ${ }^{\circledR}$ and Quizno's ${ }^{\circledR}$ and Subway $^{\circledR}$ - all these different types of commercials it makes us feel comfortable to the point that, hey, we need to get that because they've got us on the commercial, eating the same type of burger or whatever.'

'You see these rappers doing these commercials for Burger King ${ }^{\circledR} \ldots$ and these kids associate that product with them. So maybe that means if you eat a Whopper like this rapper over here does, that makes you cool like this rapper.'

\section{Attitudes about food marketing practices}

We asked caregivers to share their views about food marketing practices impacting African-American children. There were multiple sub-themes in our analysis, including whether food companies are generally helping or hurting residents of African-American communities with their marketing practices, company loyalty and uncertainty about the overall impact of food companies on AfricanAmerican youth.

When directly asked, over half of caregiver discussions referenced food company practices as being harmful:

'... it's a great concern because they [food companies] do try to get them to buy certain foods, like I said, and most of them are unhealthy. So, I don't know it's just like these children growing up now don't have a choice of something to me.'

Other caregiver discussions, however, focused on how food companies help and/or positively impact AfricanAmerican communities. A sentiment expressed by these caregivers focused on how food companies often support extracurricular activities for their children. From academic scholarships and fundraisers, to community events, to paying for scoreboards at the local sports field, food companies are providing financial resources to communities that may otherwise not get these programmes or services:

'But there are some companies that, especially some restaurants, because you have Pizza Hut ${ }^{\circledR}$ giving so many scholarships to their employees or to high school students. And this motivates them and then you have those coupon books where they can buy certain product and that contributes towards their education.'

Some caregivers also described a sense of loyalty to certain companies who targeted African Americans as if there was some apparent indebtedness:

'...well I know my sister, she always talks about supporting Coke ${ }^{\circledR}$ because Coca-Cola has sponsored that game, I guess for years, I do not know how long, but she always says let us buy Coke ${ }^{\circledR}$ products because Coke ${ }^{\circledR}$ always sponsors that classic [college football game] and the Food World also sponsored it, we need to support Food World and we support Coke $^{\circledR}$ because they always sponsor that game.'

Yet there were others who expressed ambivalence. This was primarily couched in a theme of targeted marketing is good business practice and caregivers must take personal responsibility to limit child exposure to advertisements and promotion of unhealthy food:

'Well they [food companies] are there to sell a product, and we are there to shield and protect our children. So, it's incumbent upon the parents to protect the children, which we are not doing a very good job when it comes to the kinds of food that they eat.'

In summary, participants provided multiple insights about how the food marketing environment influences African-American children's diets. In general, participants expressed concerns about health consequences of unhealthy diets and lack of access to healthier and affordable food options in their communities. They also described various promotional activities that influenced food purchase and consumption including television and print advertisements, celebrity or character endorsements, and discounted/combo meals. Participants were also familiar with several food companies/restaurants who sponsored community events related to their children. While most recognized this as partly a promotional activity, there was limited consensus about this type of marketing practice being harmful to African-American communities.

\section{Discussion}

Given limitations in children's ability to critically analyse and evaluate the intent of persuasive messages ${ }^{(46-48)}$ and ever-increasing exposure to promotion and advertising, researchers and policy makers need to better understand the extent to which food marketing practices are perceived to influence the food consumption of younger children. Despite the excess burden of obesity and diet-related diseases among minority populations, racial/ethnic health disparities have not been central to policy discussions regarding corporate marketing practices linked to excess energy intake ${ }^{(49)}$.

The present study is among the first to examine the perceptions of caregivers of young African-American children on aspects of the food marketing environment. Findings presented here suggest that caregivers of young African-American children in this area are well aware of the health consequences of overweight and obesity and readily understand the links between excess energy intake and weight status. They further articulated a myriad 
of influencing factors related to their food marketing environment. For example, caregivers expressed concern about children's strong preferences for foods (product) with low nutritional value (e.g. 'junk' foods). Such energy-dense food and beverage items have been recognized as being highly palatable, particularly among African Americans where there is biological evidence supporting a higher preference for high-fat, high-energy and sweet foods than among whites ${ }^{(13,50)}$. Further, advances in food product innovation in recent decades have led to the development of foods and beverages that are both highly palatability and faster to consume ${ }^{(14)}$; characteristics also linked to energy overconsumption and obesity.

Like previous research ${ }^{(38,39,51)}$, our findings also suggest that caregivers are aware of the influence of cost (price), food access (place) and advertisement (promotion) on children's food choices. While much of what was suggested as influencing intake could apply to youth regardless of race/ethnicity, caregivers appeared keenly aware of known targeted marketing techniques including the use of African-American actors in commercials, ethnic music and music artists, and ad placement during highly viewed shows by the target audience.

While public health officials have called for the restriction of food marketing to children worldwide ${ }^{(31)}$, public support for restrictions in the USA is less clear. Despite a general awareness of targeted marketing techniques and their perceived influence on eating behaviours and health risk, participants were not quick to blame food and/or marketing companies. Many caregivers focused on the good done by these companies in their communities and they expressed loyalty as a result. Similar to an earlier study ${ }^{(51)}$, African-American caregivers in our study seemed to differentiate between a food retailer's promotion of unhealthy food to children and other promotional activities (e.g. sponsorship of community events). While commercials and print advertisement of unhealthy foods aimed at children were generally seen as harmful, sponsorships and many of the other promotional activities were considered as supportive and/or good business practices. As such, framing the demand for unhealthy food marketing restrictions in the African-American community as a social justice issue (i.e. emphasizing community responsibility and government intervention to ensure equity) may be challenged by community perceptions of the cause of the injustice. That is, participants in the present study were more likely to attribute children's unhealthy eating to lack of parental control (i.e. personal responsibility) rather than inequitable food marketing practices (i.e. corporate manipulation). This is also consistent with previous work suggesting consumers may have difficulty distinguishing between calls for limitations on advertisement of unhealthy foods/beverages to children and restrictions of the sale and purchase of these items ${ }^{(51)}$. The latter has been perceived as going too far and potentially infringing upon individual rights and free enterprise.

Findings from our exploratory study should be interpreted with caution given its limitations. First, opinions expressed by our participants may not reflect those of all caregivers of African-American children. Our sample included a self-selected group with some relationship to our community partner; however, demographic characteristics of the sample are similar to their community-at-large. Second, responses provided were based on caregivers' reflection on what influences their child's purchasing and consumption behaviours. Objective measures of actual purchase and consumption and metrics for decision making at the time of purchase were beyond the scope of the study. Finally, the interpretation of interview data is subject to bias by the researchers. To minimize subjectivity, transcripts were independently coded by multiple researchers and results were reviewed by community partners involved in data collection and interpretation of findings.

Despite these limitations, the present study offers unique insight into the perceptions of caregivers of young African-American children concerning aspects of their food marketing environment. There is a need for critical dialogue between community members, policy makers and food marketers to galvanize the demand for healthy food. However, the road to achieve this goal will likely require modified strategies than those that may have supported other movements in these communities.

\section{Acknowledgements}

Sources of funding: This research was funded through a Robert Wood Johnson Foundation grant to the African American Collaborative Obesity Research Network. Conflicts of interest: None. Authors' contributions: M.L.B., A.O.-Y. and J.D.A. designed the study. I.H., N.I. and M.L.B. conducted the analysis. M.L.B. and R.W. interpreted the analysis. M.L.B. wrote the manuscript. All authors made conceptual contributions to the manuscript. Acknowledgements: The authors would like to express their appreciation to the Founder of Congregations for Public Health, Inc. (CPH), Rev. Donald Solomon and the CPH Neighborhood Outreach Specialists working on this study: Denise Benson, Eloise Gaffney, Clara Griggs, Helen Smith and Patricia Walker. They would also like to thank their graduate research assistants: Herpreet Thind, MPH and Monique Mullins, MPH. They further appreciate the input and guidance from Vikki Lassiter, Sonya Grier, Katie Disantis and Shiriki Kumanyika in the Research, Evaluation and Dissemination Core of the African American Collaborative Obesity Research Network throughout various phases of this project. Finally, the authors are forever grateful to the caregivers participating in the study. 


\section{References}

1. Bethell C, Simpson L, Stumbo S et al. (2010) National, state, and local disparities in childhood obesity. Health Aff (Millwood) 29, 347-356.

2. Abrams P \& Levitt Katz LE (2011) Metabolic effects of obesity causing disease in childhood. Curr Opin Endocrinol Diabetes Obes 18, 23-27.

3. Robinson S (2006) Victimization of obese adolescents. J Sch Nurs 22, 201-206.

4. Young-Hyman D, Tanofsky-Kraff M, Yanovski SZ et al. (2006) Psychological status and weight-related distress in overweight or at-risk-for-overweight children. Obesity (Silver Spring) 14, 2249-2258.

5. Jemal A, Siegel R, Ward E et al. (2008) Cancer statistics, 2008. CA Cancer J Clin 58, 71-96.

6. Mensah GA, Mokdad AH, Ford ES et al. (2005) State of disparities in cardiovascular health in the United States. Circulation 111, 1233-1241.

7. Flegal KM, Ogden CL, Yanovski JA et al. (2010) High adiposity and high body mass index-for-age in US children and adolescents overall and by race-ethnic group. $\mathrm{Am} \mathrm{J}$ Clin Nutr 91, 1020-1026.

8. Ogden CL, Carroll MD, Curtin LR et al. (2010) Prevalence of high body mass index in US children and adolescents, 2007-2008. JAMA 303, 242-249.

9. Ogden CL, Carroll MD, Curtin LR et al. (2006) Prevalence of overweight and obesity in the United States, 1999-2004. JAMA 295, 1549-1555.

10. Ogden CL, Carroll MD \& Flegal KM (2008) High body mass index for age among US children and adolescents, 2003-2006. JAMA 299, 2401-2405.

11. Crespo CJ, Smitt E, Andersen RE et al. (2000) Race/ ethnicity, social class and their relation to physical inactivity during leisure time: results from the third National Health and Nutrition Examination Survey, 1988-1994. Am J Prev Med 18, 46-53.

12. Giammattei J, Blix G, Marshak HH et al. (2003) Television watching and soft drink consumption: associations with obesity in 11- to 13-year-old schoolchildren. Arch Pediatr Adolesc Med 157, 882-886.

13. Troiano RP, Briefel RR, Carroll MD et al. (2000) Energy and fat intakes of children and adolescents in the United States: data from the National Health and Nutrition Examination Surveys. Am J Clin Nutr 72, 5 Suppl., 1343S-1353S.

14. Zimmerman FJ (2011) Using marketing muscle to sell fat: the rise of obesity in the modern economy. Annu Rev Public Health 32, 285-306.

15. McCarthy EJ (1960) Basic Marketing: A Managerial Approach. Homewood, IL: Richard D. Irwine.

16. Harris JL, Pomeranz JL, Lobstein T et al. (2009) A crisis in the marketplace: how food marketing contributes to childhood obesity and what can be done. Annu Rev Public Health 30, 211-225.

17. Harris JL, Bargh JA \& Brownell KD (2009) Priming effects of television food advertising on eating behavior. Health Psychol 28, 404-413.

18. Hastings G, Stead M, McDermott L et al. (2003) Review of Research on the Effect of Food Promotion to Children. Glasgow, UK: Centre for Social Marketing.

19. Hastings G, McDermott L, Angus K et al. (2006) The Extent, Nature and Effects of Food Promotion to Children: A Review of the Evidence. Geneva: WHO.

20. Chandon P \& Wansink B (2012) Does food marketing need to make us fat? A review and solutions. Nutr Rev 70, 571-593.

21. Harris JL, Schwartz MB \& Brownell KD (2010) Marketing foods to children and adolescents: licensed characters and other promotions on packaged foods in the supermarket. Public Health Nutr 13, 409-417.
22. Institute of Medicine (2006) Food Marketing to Children and Youth: Threat or Opportunity? Washington, DC: The National Academies Press.

23. Story M \& French S (2004) Food advertising and marketing directed at children and adolescents in the US. Int J Behav Nutr Phys Act 1, 3.

24. Kotler P, Armstrong G \& Starr RGS (1991) Principles of Marketing. Upper Saddle River, NJ: Prentice-Hall.

25. Grier SA \& Kumanyika SK (2008) The context for choice: health implications of targeted food and beverage marketing to African Americans. Am J Public Health 98, 1616-1629.

26. Kumanyika S \& Grier S (2006) Targeting interventions for ethnic minority and low-income populations. Future Child 16, 187-207.

27. Grier S (2005) Obesity and targeted food marketing to ethnic minority youth. In Marketing and Public Policy Conference, pp. 160-161 [J Langenderfer, DL Cook and JD Williams, editors]. Washington, DC: American Marketing Association.

28. Powell LM, Szczypka G \& Chaloupka FJ (2007) Adolescent exposure to food advertising on television. Am J Prev Med 33, 4 Suppl., S251-S256.

29. Powell LM, Szczypka G, Chaloupka FJ et al. (2007) Nutritional content of television food advertisements seen by children and adolescents in the United States. Pediatrics 120, 576-583.

30. Roberts D, Foehr UG \& Rideout V (2005) Generation M: Media in the Lives of 8-18 Year-Olds. Menlo Park, CA: Kaiser Family Foundation.

31. World Health Organization (2006) Marketing of Food and Non-Alcoholic Beverages to Children. Report of a WHO Forum and Technical Meeting, Oslo, Norway, 2-5 May 2006. Geneva: WHO; available at http://www.who.int/ dietphysicalactivity/publications/Oslo\%20meeting\%20layout $\% 2027 \% 20$ NOVEMBER.pdf

32. Federal Trade Commission (2008) Marketing Food to Children and Adolescents. A Review of Industry Expenditures, Activities, and Self-Regulation. A Report to Congress. Washington, DC: FTC; available at http://www.ftc.gov/os/ 2008/07/P064504foodmktingreport.pdf

33. Taylor WC, Poston WSC, Jones L et al. (2006) Environmental justice: a framework for collaboration between the public health and parks and recreation fields to study disparities in physical activity. J Phys Act Health 3, Suppl. 1, S30-S54.

34. Barry CL, Brescoll VL, Brownell KD et al. (2009) Obesity metaphors: how beliefs about the causes of obesity affect support for public policy. Milbank $Q$ 87, 7-47.

35. Goren A, Harris JL, Schwartz MB et al. (2010) Predicting support for restricting food marketing to youth. Health Aff (Millwood) 29, 419-424.

36. Brownell KD, Kersh R, Ludwig DS et al. (2010) Personal responsibility and obesity: a constructive approach to a controversial issue. Health Aff (Millwood) 29, 379-387.

37. Speers S, Goren A, Harris JL et al. (2009) Public Perceptions of Food Marketing to Youth: Results of the Rudd Center Pubic Opinion Poll. New Haven, CT: Rudd Center for Food Policy and Obesity, Yale University; available at http://www. yaleruddcenter.org/resources/upload/docs/what/reports/ RuddReportPublicPerceptionsFoodMarketingYouth2009.pdf

38. Grier SA, Mensinger J, Huang SH et al. (2007) Fast food marketing and children's fast food consumption: exploring parental influences in an ethnically diverse sample. J Public Policy Mark 26, 221-235.

39. Bibeau WS, Saksvig BI, Gittelsohn J et al. (2012) Perceptions of the food marketing environment among African American teen girls and adults. Appetite 58, 396-399.

40. US Census Bureau (2000) State and County Quick Facts. Population Estimates. http://quickfacts.census.gov (accessed July 2009). 
41. Israel BA, Schulz AJ, Parker EA et al. (2003) Critical issues in developing and following community-based participatory research principles. In Community-Based Participatory Research for Health, pp. 56-73 [M Minkler and N Wallerstein, editors]. San Francisco, CA: Jossey-Bass.

42. US Census Bureau (2000) Population Finder: Fact Sheet. http://factfinder.census.gov (accessed August 2011)

43. Spradley J (1979) The Ethnographic Interview. New York: Holt, Rinehart and Winston.

44. Creswell JW (2007) Qualitative Inquiry and Research Design: Choosing Among the Five Approaches, 2nd ed. Thousand Oaks, CA: Sage Publications.

45. Glaser B \& Strauss A (1967) The Discovery of Grounded Theory. Chicago, IL: Aldine.

46. Blosser BJ \& Roberts DF (1985) Age differences in children's perceptions of message intent: responses to TV-news, commercials, educational spots, and public-service announcements. Commun Res 12, 455-484.
47. Livingstone S \& Helsper EJ (2006) Does advertising literacy mediate the effects of advertising on children? A critical examination of two linked research literatures in relation to obesity and food choice. J Commun 56, 560-584.

48. Wartella E (1980) Children and television: the development of the child's understanding of the medium. In Mass Communication Review Yearbook, vol. 1, pp. 516-553 [C Wilhoit and H DeBock, editors]. Beverly Hills, CA: Sage Publications.

49. Grier SA \& Kumanyika S (2010) Targeted marketing and public health. Annu Rev Public Health 31, 349-369.

50. Schiffman SS, Graham BG, Sattely-Miller EA et al. (2000) Elevated and sustained desire for sweet taste in AfricanAmericans: a potential factor in the development of obesity. Nutrition 16, 886-893.

51. Ustjanauskas AE, Eckman B, Harris JL et al. (2010) Focus Groups with Parents: What Do They Think About Food Marketing to Their Kids? New Haven, CT: Rudd Center for Food Policy and Obesity, Yale University. 